\title{
CROWDING-OUT EFFECT OF FINANCIAL INCENTIVES FOR HOUSEHOLDS TO RECYCLE WASTE
}

\author{
JIRI REMR \\ Institute for Evaluations and Social Analyses, Czech Republic
}

\begin{abstract}
Willingness of individuals to recycle their waste is driven by a wide range of factors. These may be distinguished as intrinsic, for example perceived importance of recycling, and extrinsic, e.g. commandand-control interventions or financial incentives in a form of landfill taxes, deposits, charges, and fees. In order to increase the participation rate, specific policy measures and interventions are introduced. Some of these interventions, like educational campaigns, are focused on intrinsic motivation of residents, whereas some other measures are using financial stimuli to affect people's recycling behavior directly. In this respect, the crowding-out effect might occur when financial incentives might reduce the effect of intrinsic factors. This paper reports on responsiveness of residents to the direct and indirect incentives. The purpose of this analysis was to test the crowding-out hypothesis supposing that direct incentives are replacing the intrinsic motivation to recycle. The presented data is based on a nationwide survey ( $\mathrm{n}=1.579)$ that was conducted in the Czech Republic during 2017 and confirms the hypothesis for a large part of the population $(50 \%)$. However, it was also found that one fifth of the sample is responsive only to the direct incentives. Therefore, the crowding-out effect is not confirmed for a segment of the population. It seems that direct and indirect incentives may not be mutually exclusive. For some individuals the direct and indirect measures might support each other and together may increase positive impacts on recycling behavior. It is also highly recommended to consider the context within which the given measures are to be implemented. Under certain circumstances, such as high intrinsic motivation of residents, the launch of direct measures may not be reasonable.
\end{abstract}

Keywords: recycling, crowding-out effect, attitude, behavioral change, intrinsic motivation, waste management, direct incentives.

\section{INTRODUCTION}

This paper compares the responsiveness of residents to direct (typically financial) and indirect measures (usually in a form of educational campaigns). It also estimates the usefulness of replacing the currently-used measures and policies aimed at affecting the recycling behavior of households with new ones. In making such comparison, I hypothesize that a crowding-out effect might occur when indirect measures are replaced with direct incentives. However, there is a rival concept besides the crowding-out hypothesis that considers the direct incentives as having an additional effect strengthening the efficacy of indirect measures. According to the rival hypothesis, the direct incentives might also encourage the different individuals (i.e. new segments of the population) that are resistant toward indirect measures.

The results of comprehensive survey research are presented in this paper. Besides the description of recycling behavior and identification of its key determinants a specific module was devoted to the perceived significance of direct incentives and to other motivations to recycle that respondents might have. In spite of the discussions in scientific literature, no policy instruments for affecting the recycling behavior are widely recommended. These questions are not exclusive to waste management system in the Czech Republic and therefore I believe that the findings could inspire also the others. 


\section{TYPES OF INCENTIVES}

Stakeholders responsible for waste management systems (i.e. the municipalities) use a wide range of measures and policies aimed at affecting the recycling behavior of households and increasing participation rate. These interventions might have a form of command-and-control stimuli such take-back schemes, as well as market-based incentives (e.g. landfill taxes, deposits, charges, and fees). Such measures are intended to change the behavior of individuals directly, while other measures work indirectly. Indirect measures, which may come in the form of educational campaigns, are used primarily to challenge the intrinsic motivations of individuals and build awareness with the expectation that such attitudinal change will be followed by a change in behavioral patterns.

Financial incentives such as deposit-refunds or marginal pricing were found by some scholars to be ineffective [1]-[4]. Moreover, Vining and Ebreo [5] stated that it is not financial rewards but desirable environmental results, which drives people to recycle. De Young [6] added that some people recycle for their personal satisfaction and not for a financial reward. The main obstacle to participation in recycling is then a lack of knowledge as De Young [6], Valerio et al. [7], Hahn and Stavins [8], McDonald and Oates [9] or Ewing [10] found. McDonald and Oates [9] or Oskamp et al. [11] stated that knowledge about recycling has been identified as the key difference between recyclers and non-recyclers (the amount of information about recycling was different between these two groups).

In practice, the stakeholders responsible for waste management systems often consider replacing currently-used measures with different ones, anticipating the need to improve effectiveness of their waste management systems and seeking to increase participation rate. However, the key question is whether such changes might yield the desired improvement.

\section{THE CASE OF THE CZECH REPUBLIC}

According to current legislation (Section 17 of the Czech Waste Act No. 185/2001 Coll.), residents are obliged to recycle all waste produced in the households. However, only $14 \%$ of the population is aware about this provision. Moreover, enforcing the legal obligation to recycle is hardly feasible; especially among those living in condominiums, it is practically impossible to identify who recycles and who does not. From the perspective of effectiveness it is important to highlight that legal obligation (even enforced by sanctions) is not an indispensable prerequisite for recycling. As Abbott et al. [12] or Kirakozian [3] reported, when social norms are internalized by individuals, sanctions are not necessary.

Direct incentives are used only by some municipalities, so they have only marginal impact on the overall participation rate. On the other hand, indirect measures are a key driver of recycling. Since 2003, nationwide educational campaign has worked to increase residents' awareness of recycling and to change their behavior to favor more recycling. The nationwide campaign has been supplemented by regional campaigns that usually share the same message but use local media and specifically communicate the practical information concerning recycling such as schedule of waste collection or types of waste suitable for recycling.

To summarize, the current participation rate of $72 \%$ [13] has been achieved by indirect measures rather than by the direct ones.

\section{METHOD USED IN STATISTICAL ANALYSIS}

\subsection{Description of variables}

Two rival constructs were defined, the first of which is responsiveness to indirect measures whereas the second represents responsiveness to direct ones. Further analysis examines how 
the two types of responsiveness relate to each other and compares the profiles of respondents who are responsive to each measure. Finally, an important descriptor is the variable that reflects current recycling habits.

\subsubsection{Responsiveness to indirect measures}

Responsiveness to indirect measures reflects the intrinsic motivations of individuals to recycle. Previous studies [3], [12], [14], [15] have shown that such motivations are associated with the amount of information that an individual has about recycling [16], with the degree of routinization, i.e. to what extent recycling is embedded in people's lives [17], [18], and with individual responsibility for the environment [19]. Therefore, the construct is based on three following variables.

The first variable reflects the respondents' interest in receiving more information on recycling. In this question, an emphasis was put on practical rather than general information. Distinguishing general and practical (or instrumental) information comes from Barr [20], who argued that general knowledge comprises information about the waste management system, its usefulness, and reminds individuals to separate their waste whereas instrumental knowledge covers practical information related to recycling within the given circumstances. Therefore, instrumental information focuses on types of materials collected, on localization of containers, etc. Previous studies [21], [22] found that instrumental knowledge is a better predictor of recycling than the general knowledge. The second variable is an agreement with statement: "Recycling is part of my lifestyle." This variable measures the extent of adoption of behavioral patterns associated with recycling. It represents the extent to which recycling is embedded in the respondent's life. This variable has proven to be valid and it is considered a strong predictor of recycling [23]. The third variable tackles the issue of personal responsibility for waste. It is indicated by an agreement with statement: "Recycling my waste is solely my own duty." This attitude reflects strong intrinsic motivation to recycle.

In their original form, all three variables form the Likert scale with four options ranging from "definitely agree" (1) to "definitely disagree" (4). Values of all variables were summarized and finally divided into three categories reflecting the degree of responsiveness. Agreement with the given variables reflects strong intrinsic motivation to recycle, or more precisely, high responsiveness to indirect measures. Table 1 shows that two fifths $(41 \%)$ of respondents are highly responsive to indirect incentives on the other hand, one fifth $(21 \%)$ of all respondents has low intrinsic motivation to recycle. Among them, we cannot rely on their self-motivation to recycle and therefore their willingness to recycle has to be increased by other stimuli.

\subsubsection{Responsiveness to direct measures}

Similarly as in the case of indirect measures, three independent variables were used to indicate responsiveness to direct incentives. The rationale behind this construct stems from the desire of respondents to receive any kind of financial benefit as a reward or compensation for their recycling effort. The construct is therefore based on an overall acceptance of receiving a financial reward for recycling. The other two variables reflect the two major

Table 1: Responsiveness to indirect incentives.

\begin{tabular}{lccc}
\hline Coding & Frequency & Mean & Std. Deviation \\
\hline $1=$ High & $41 \%$ & & \\
$2=$ Moderate & $38 \%$ & 1.8 & 0.759 \\
$3=$ Low & $21 \%$ & & \\
\hline
\end{tabular}


approaches that are usually discussed [24], i.e. entitling recyclers to discount from fees, and price premium (or fine) that the non-recyclers must to pay.

The first variable comes from the agreement with statement that "People should receive a financial reward for their recycling efforts." The second indicator represents an interest of respondents in receiving a discount as a reward for recycling. The third component of this construct is an agreement with the statement: "Those who do not recycle should pay more than those who recycle." Agreement with these statements reflects a strong craving for financial reward and thus high responsiveness to direct measures.

Similarly as in case of indirect measures, all three questions form the Likert scale with four options ranging from "definitely agree" (1) to "definitely disagree" (4). They were summarized and finally divided into three groups reflecting the degree of responsiveness. As Table 2 indicates, $44 \%$ of respondents are highly responsive to direct measures. On the other hand, $17 \%$ are not driven by direct incentives.

\subsubsection{Declared recycling}

Self-reported data on recycling behavior was also collected. It is a common approach to study recycling; the same method can be found in Derksen and Gartrell [25], Miliute-Plepiene et al. [26] or Fullerton and Kinnaman [27]. However, this approach has some limitations (see [28]) because of overestimation of declared recycling, typically caused by a social desirability effect. Since exact data related to actual recycling are not available, the focus on self-reported recycling is acceptable.

Table 3 brings data for the analyzed sample showing that $44 \%$ declare they regularly recycle, $37 \%$ do so occasionally and $19 \%$ declare that they do not recycle at all. Such findings are consistent with other data, especially on participation rate, which is $72 \%$ [13]. The higher self-reported data are caused by the aforementioned social desirability effect.

\subsection{Sample, sampling technique and data collection method}

The target population is the general population of the Czech Republic aged 18-74 comprising only Czech residents living permanently in the Czech Republic.

The sampling technique applied was the multistage random procedure using random route. Since no adequate sampling frame (register or list of residents) was available, primary sampling units were selected. Subsequently, within each primary sampling unit, addresses were identified and households were selected. Finally, the interviewers visited the preselected addresses, attempted to contact the households, identified the prospective respondent

Table 2: Responsiveness to direct incentives.

\begin{tabular}{lccc}
\hline Coding & Frequency & Mean & Std. Deviation \\
\hline $1=$ High & $44 \%$ & & \\
$2=$ Moderate & $39 \%$ & 1.73 & 0.734 \\
$3=$ Low & $17 \%$ & & \\
\hline
\end{tabular}

Table 3: Respondents recycling.

\begin{tabular}{lc}
\hline Coding & Frequency \\
\hline $1=$ Recycle regularly & $44 \%$ \\
$2=$ Recycle occasionally & $37 \%$ \\
$3=$ Do not recycle at all & $19 \%$ \\
\hline
\end{tabular}


using the Kish table [29] and invited the relevant individual to participate. Altogether 186 primary sampling units throughout the Czech Republic were selected; within each of these units a maximum of 20 addresses were identified. Interviewers contacted 3.148 households and performed 1.611 interviews (response rate was 51.2\%). However, due to incompleteness of some of these interviews, when respondents refused to provide key socio-demographic data, the datafile comprised 1.579 cases used for analysis. Fieldwork took place during March 2017 and average duration of an interview was approx. 35 minutes. From all 1.611 interviews, $20 \%$ were supervised by check-backs and verified in terms of compliance with ethical standards (especially confidentiality, informed consent, and non-maleficence).

\section{RESULTS AND DISCUSSION}

\subsection{Comparison of responsiveness to direct and indirect incentives}

From survey data it is obvious that the responsiveness to direct and indirect incentives is similar, even though the responsiveness to direct measures is higher. Table 4 shows that among the whole sample, $69 \%$ of respondents declared their interest in receiving financial reward as a compensation for their recycling effort. At the same time, $63 \%$ of respondents' recycling behavior is solely driven by intrinsic motivation. The identified difference is statistically significant and therefore the very first conclusion would be that an interest in direct incentives is stronger than the interest in indirect measures.

However, from Table 4 it is also obvious that for $50 \%$ of all respondents, both types of measures are effective. These respondents, who represent the largest segment, are primarily driven by intrinsic motivation but they call for financial reward as well. For these respondents the crowding-out hypotheses is relevant. The past behavior of this segment already proved that indirect measures are strong enough to drive recycling behavior. The vast majority of respondents in this segment (94\%) declare that they recycle and they would do so even without financial reward. As already explained, there are no such measures implemented in the Czech Republic. Therefore, changing the logic of waste management system and introducing the direct measures would therefore gain only marginal effect on participation rate.

The second segment (19\%) represents those who are responsive to direct incentives but they do not seem to be responsive to indirect measures. Therefore, the crowding-out effect will not appear within this segment. When these people are resistant to indirect measures, targeting them by indirect stimuli might lead to suboptimal results, i.e. participation rate would not increase. This estimate is confirmed by current data showing that $31 \%$ of nonrecyclers are within this segment, which is a significantly higher share than in all other segments.

Table 4: Responsiveness-based segments.

\begin{tabular}{llllr}
\hline & & \multicolumn{3}{c}{ Responsiveness to } \\
indirect incentives & Total \\
& & High & Low \\
\cline { 3 - 5 } Responsiveness to direct incentives & High & $50 \%$ & $19 \%$ & $\mathbf{6 9 \%}$ \\
& Low & $13 \%$ & $18 \%$ & $\mathbf{3 1 \%}$ \\
& Total & $\mathbf{6 3 \%}$ & $\mathbf{3 7 \%}$ & $\mathbf{1 0 0 \%}$ \\
\hline
\end{tabular}


Table 5: Comparison of selected socio-demographic characteristics.

\begin{tabular}{llcc}
\hline Variables & Elementary & $\begin{array}{c}\text { Responsiveness to } \\
\text { direct incentives }\end{array}$ & $\begin{array}{c}\text { Responsiveness to } \\
\text { indirect incentives }\end{array}$ \\
\hline \multirow{5}{*}{ Achieved } & Vocational & $19 \%$ & $10 \%$ \\
education & Secondary & $32 \%$ & $36 \%$ \\
& University & $38 \%$ & $39 \%$ \\
& Total & $12 \%$ & $15 \%$ \\
\multirow{5}{*}{ Type of residence } & Family house & $\mathbf{1 0 0 \%}$ & $\mathbf{1 0 0 \%}$ \\
& Apartment house & $22 \%$ & $42 \%$ \\
& Block of flats & $46 \%$ & $21 \%$ \\
& Total & $\mathbf{1 0 0 \%}$ & $37 \%$ \\
\multirow{5}{*}{ Size of settlement } & $25 \%$ & $\mathbf{1 0 0 \%}$ \\
& Less than 3,000 inhabitants & $33 \%$ & $29 \%$ \\
& $3,000-23,999$ inhabitants & $42 \%$ & $35 \%$ \\
\cline { 2 - 4 } & 24,000 inhabitants or more & $\mathbf{1 0 0 \%}$ & $36 \%$ \\
& Total & $\mathbf{1 0 0 \%}$
\end{tabular}

Note: $\left[\chi^{2}=6.208, \mathrm{df}=3, \mathrm{p}=0.102\right.$, Mann-Whitney $\left.\mathrm{U}=18708.000, \mathrm{p}=0.099\right] ;\left[\chi^{2}=4.782, \mathrm{df}=2, \mathrm{p}=0.092\right.$, Mann-Whitney $\mathrm{U}=18348.000, \mathrm{p}=0.035] ;\left[\chi^{2}=1.544, \mathrm{df}=2, \mathrm{p}=0.462\right.$, Mann-Whitney $\left.\mathrm{U}=19388.000, \mathrm{p}=0.217\right]$.

The third segment (13\%) represents people with contrary attitudes toward recycling compared to the previous segment. These respondents are responsive to indirect measures but they also show low responsiveness to direct incentives. If these people recycle, they do so because of intrinsic motivation without needing any financial rewards and therefore the crowding-out effect might appear among these respondents. Implementation of the direct incentives would be redundant and it would only replace the intrinsic motivation with financial reward. It is worth mentioning that $94 \%$ of respondents within this segment declare they already recycle.

The fourth segment representing $18 \%$ of the total sample are those who show reluctance to both types of measures. For these individuals it will be a challenge to find the relevant motivational driver; this segment is heterogeneous in terms of determinants affecting the perception of recycling and intention to recycle.

Further analysis is focused on the comparison of the segments two and three; it also aims to profile both segments and to find significant differences that might help to understand the context and circumstances concerning the responsiveness to different kinds of incentives.

\subsection{Detailed analysis of responsiveness}

Within the segment of those who are responsive to direct incentives, the most responsive are the people with lower education and generally with lower socio-economic status. The impact of socio-demographic characteristics on recycling has been explored in various studies and as Vicente and Reis [30] stated the results are inconsistent. Low correlation of sociodemographic characteristics with recycling behavior is confirmed by e.g. Oskamp et al. [11] and Barr [20]. Nevertheless, Barr [20] admits that some relationships between socialdemographic characteristics and recycling do exist. Similarly, Schultz and Zelezny [31], who studied environmental concerns of households and their socio-demographic characteristics identified many statistically significant associations. The data that I have analyzed confirms the results of studies of Barr [20] or Schultz and Zelezny [31], showing in Table 5 that some of the socio-demographic characteristics might serve as reliable predictors of recycling. 
Table 5 also shows that those who are most responsive to direct incentives are the individuals who live in larger cities and those who reside in blocks of flats or condominiums. However, these types of residence offer the lowest chances to implement direct measures because in such residential areas it is difficult to differentiate which households recycle and which do not with necessary high precision and certainty.

\subsection{Expected effectiveness of direct and indirect incentives}

Residents who are responsive to the direct incentives may represent a promising amount of households. In case of The Czech Republic, it might be approximately 500.000 households. However, it would be naïve to expect that for all of those households a lack of financial reward is the only barrier to start recycling. Detailed analysis of the self-reported data summarized in Table 6 shows that individuals in this segment produce the least amount of waste. Whereas those who are responsive to indirect measures estimate the overall production of waste within their households to $51 \mathrm{~kg}$ per month, respondents in the other segment provide the mean estimate of only $43 \mathrm{~kg}$. Table 6 also shows that the share of recyclers is significantly higher among individuals who are responsive to indirect measures $(90 \%$ when $54 \%$ recycles regularly and another $36 \%$ at least occasionally). Within the other segment of the $69 \%$ of recyclers, $27 \%$ recycle regularly and $42 \%$ occasionally. Differences in recycling behavior between both segments is also documented by the number of recycled commodities and volatility of recycling when those who are responsive to indirect incentives (driven by their intrinsic motivation supported with the educational campaigns) are more zealous about recycling than the other segment. Therefore, the direct incentives launch might have only marginal effect on recycling.

Table 6: Comparison of recycling behavior.

\begin{tabular}{|c|c|c|c|}
\hline \multicolumn{2}{|l|}{ Variables } & $\begin{array}{l}\text { Responsiveness to } \\
\text { direct incentives }\end{array}$ & $\begin{array}{c}\text { Responsiveness } \\
\text { to indirect } \\
\text { incentives } \\
\end{array}$ \\
\hline \multicolumn{2}{|c|}{$\begin{array}{l}\text { Reported monthly amount of waste } \\
\text { (in kg per household) }\end{array}$} & 43 & 51 \\
\hline \multirow{4}{*}{ Recycling } & Regularly & $27 \%$ & $54 \%$ \\
\hline & Occasionally & $42 \%$ & $36 \%$ \\
\hline & Not at all & $31 \%$ & $10 \%$ \\
\hline & Total & $100 \%$ & $100 \%$ \\
\hline \multirow{3}{*}{$\begin{array}{l}\text { Number of recycled } \\
\text { commodities* }\end{array}$} & Only some selectively & $77 \%$ & $50 \%$ \\
\hline & All possible & $24 \%$ & $50 \%$ \\
\hline & Total & $100 \%$ & $100 \%$ \\
\hline \multirow{3}{*}{ Volatility of recycling* } & Low & $63 \%$ & $76 \%$ \\
\hline & High & $38 \%$ & $24 \%$ \\
\hline & Total & $100 \%$ & $100 \%$ \\
\hline
\end{tabular}


Table 7: Comparison of attitudes towards recycling.

\begin{tabular}{|c|c|c|c|}
\hline Variables & & $\begin{array}{c}\text { Responsiveness to } \\
\text { direct incentives }\end{array}$ & $\begin{array}{l}\text { Responsiveness to } \\
\text { indirect incentives }\end{array}$ \\
\hline \multirow{6}{*}{$\begin{array}{l}\text { Self-evaluation of } \\
\text { recycling }\end{array}$} & Excellent & $3 \%$ & $22 \%$ \\
\hline & Good & $36 \%$ & $34 \%$ \\
\hline & Acceptable & $42 \%$ & $35 \%$ \\
\hline & Poor & $13 \%$ & $6 \%$ \\
\hline & Weak & $6 \%$ & $3 \%$ \\
\hline & Total & $100 \%$ & $100 \%$ \\
\hline \multirow{4}{*}{$\begin{array}{l}\text { Awareness about } \\
\text { positive impacts of } \\
\text { recycling }\end{array}$} & High & $35 \%$ & $50 \%$ \\
\hline & Moderate & $27 \%$ & $27 \%$ \\
\hline & Low & $38 \%$ & $23 \%$ \\
\hline & Total & $100 \%$ & $100 \%$ \\
\hline \multirow{3}{*}{$\begin{array}{l}\text { Satisfaction with } \\
\text { containers localization }\end{array}$} & Satisfied & $73 \%$ & $86 \%$ \\
\hline & Dissatisfied & $27 \%$ & $14 \%$ \\
\hline & Total & $100 \%$ & $100 \%$ \\
\hline \multirow{3}{*}{$\begin{array}{l}\text { Reported containers' } \\
\text { overfullness }\end{array}$} & Often or sometimes & $76 \%$ & $61 \%$ \\
\hline & Rarely or never & $24 \%$ & $39 \%$ \\
\hline & Total & $100 \%$ & $100 \%$ \\
\hline
\end{tabular}

Note: $\left[\chi^{2}=31.058, \mathrm{df}=4, \mathrm{p}=0.000\right.$, Mann-Whitney $\left.\mathrm{U}=9201.500, \mathrm{p}=0.000\right] ; \quad\left[\chi^{2}=12.913, \mathrm{df}=2, \mathrm{p}=0.002\right.$, MannWhitney $\mathrm{U}=15526.500, \mathrm{p}=0.000] ;\left[\chi^{2}=7.910, \mathrm{df}=1, \mathrm{p}=0.005\right.$, Mann-Whitney $\left.\mathrm{U}=13431.000, \mathrm{p}=0.005\right] ;\left[\chi^{2}=9.122\right.$, $\mathrm{df}=1, \mathrm{p}=0.003$, Mann-Whitney $\mathrm{U}=12684.000, \mathrm{p}=0.003]$.

Apart from the declared behavioral differences, there are also substantial gaps in attitudes toward recycling between the two compared segments as indicated in Table 7. Most significant differences are observed in self-evaluation of recycling and in awareness about positive impacts of recycling. Respondents who are responsive to indirect measures consider their recycling as excellent in approximately one fifth of cases whereas with the other segment there are only $3 \%$ of respondents with such self-perception. Table 7 also shows that shares of those who declare that their recycling is either poor or week are doubled among people responsive to direct incentives compared to individuals from the other segment. As for the awareness about positive impacts of recycling, high awareness was identified among half of the segment responsive to indirect measures compared to $35 \%$ in the other segment.

It was also observed that significantly more individuals in this segment consider other issues as a barrier for their recycling. These objections focus on the waste management system's infrastructure and performance. As Table 7 documents, $27 \%$ of those who are responsive to direct incentives and $14 \%$ in the other segment are dissatisfied with containers' proximity; more people responsive to direct incentives also point out that containers are sometimes or often overfilled.

\section{CONCLUSIONS}

Direct incentives do affect the decision-making of a major part of the population. However, its effect is not exclusive - a similar (or even better) result might be achieved by utilization of indirect measures. Moreover, people driven by direct incentives produce less waste and 
are more reluctant toward recycling and therefore, an increase in effectiveness of overall waste management system should not be expected.

Realistically, direct and indirect incentives may not be mutually exclusive. For some individuals these two measures might support each other and together might increase positive impact on recycling behavior. The results obtained in my study confirmed the need for adequate policies to increase participation rate, particularly amongst those who are not willing to bear recycling on their minds. Of the currently available measures, indirect incentives such as educational campaigns seem to produce an adequate impact on recycling.

Segmentation is essential in this respect: no measures affect the behavior of each member of the target group in the same way. Direct incentives might yield desired behavior (change) among some residents but may not be effective for the others. It is therefore essential to analyze attitudes and patterns of behavior within specific segments of the population.

It is also important to consider the desired goals associated with the given measures. Is it increasing the participation rate? Or increasing the effectiveness of waste management? The given incentives that are effective in increasing the participation rate might not be effective when the aim is to improve recycling effectiveness.

Finally, it is highly recommended to consider the context within which the given measures are analyzed. Merit of the presented case is a high participation rate (72\%) that was built with the use of indirect measures. Under such circumstances, it seems unreasonable to switch suddenly and in a blanket manner to direct measures. However, it may be effective within specific municipalities where the participation rate is low or where it is difficult and expensive to reach the population with indirect incentives.

\section{REFERENCES}

[1] Saphores, J.D. \& Nixon, H., How effective are current household recycling policies? Results from a national survey of U.S. households. Resources, Conservation and Recycling, 92, pp. 1-10, 2014. DOI: 10.1016/j.resconrec.2014.08.010.

[2] Miafodzyeva, S. \& Brandts, N., Recycling behavior among households: Synthesizing determinants via a meta-analysis. Waste and Biomass Valorization, 4(2), pp. 257-277, 2013. DOI: $10.1007 / \mathrm{s} 12649-012-9144-4$.

[3] Kirakozian, A., The determinants of household recycling: Social influence, public policies and environmental preferences. Applied Economics, 48(16), pp. 1481-1503, 2016. DOI: 10.1080/00036846.2015.1102843.

[4] Dewees, D.N., Pricing municipal services: The economics of user fees. Canadian Tax Journal, 50(2), pp. 586-599, 2002.

[5] Vining, J. \& Ebreo, A., What makes a recycler? A comparison of recycling motivations in four communities. Environmental Management, 16(6), pp. 785-797, 1990. DOI: $10.1007 / \mathrm{bf02645669.}$

[6] De Young, R., Encouraging environmentally appropriate behavior: The role of intrinsic motivation. Journal of Environmental Systems, 15, pp. 281-292, 1986. DOI: $10.2190 / 3$ fwv-4wm0-r6mc-2urb.

[7] Valerio, M., Gnoni, M.G. \& Tornese, F., Designing Pay-as-you-Throw schemes in municipal waste management services: A holistic approach. Waste Management, 44, pp. 188-195, 2015. DOI: 10.1016/j.wasman.2015.07.040.

[8] Hahn, R.W. \& Stavins, R., Economic incentives for environmental protection: Integrating theory and practice. The American Economic Review, 82(2), pp. 464-468, 1992.

[9] McDonald, S. \& Oates, C.J., Reasons for non-participation in a kerbside recycling scheme. Resources, Conservation and Recycling, 39(4), pp. 369-385, 2003. 
[10] Ewing, G., Altruistic, egoistic, and normative effects on curbside recycling. Environment and Behavior, 33(6), pp. 733-764, 2001.

DOI: $10.1177 / 00139160121973223$.

[11] Oskamp, S., Harrington, M., Edwards, T., Sherwood, P.L., Okuda, S.M. \& Swanson, D.L., Factors influencing household recycling behavior. Environment and Behavior, 23(4), pp. 494-519, 1991. DOI: 10.1177/0013916591234005.

[12] Abbott, A., Nandeibam, S. \& O'Shea, L., Recycling: Social norms and warm-glow revisited. Ecological Economics, 90, pp. 10-18, 2013.

DOI: 10.1016/j.ecolecon.2013.02.015.

[13] Grolmus, L., Výsledky systému EKO-KOM za rok 2016. Proceedings of the Conference 'Odpady a obce', Hradec Králové, 2017.

[14] Halvorsen, B., Effects of norms and policy incentives on household recycling: An international comparison. Discussion Papers No. 627, Statistics Norway, Research Department, 2010.

[15] Starr, J. \& Nicolson, C., Patterns in trash: Factors driving municipal recycling in Massachusetts. Resources, Conservation and Recycling, 99, pp. 7-18, 2015.

DOI: 10.1016/j.resconrec.2015.03.009.

[16] Padilla, A.J. \& Trujillo, J.C., Waste disposal and households' Heterogeneity. Identifying factors shaping attitudes towards source-separated recycling in Bogotá, Colombia. Waste Management, 74, pp. 16-33, 2018.

DOI: 10.1016/j.wasman.2017.11.052.

[17] Bom, U.B., Belbase, S. \& Bibriven Lila, R., Public perceptions and practices of solid waste recycling in the city of Laramie in Wyoming, U.S.A. Recycling, 2(3), p. 11, 2017. DOI: $10.3390 /$ recycling2030011.

[18] Velenturf, P.M., Purnell, P., Tregent, M., Ferguson, J. \& Holmes, A., Co-producing a vision and approach for the transition towards a circular economy: Perspectives from government partners. Sustainability, 10(5), 1401, 2018. DOI: 10.3390/su10051401.

[19] Johansson, K., Understanding recycling behavior: A study of motivational factors behind waste recycling. WIT Transaction on Ecology and the Environment, vol. 202, WIT Press: Southampton and Boston, pp. 401-414, 2016.

[20] Barr, S., Factors influencing environmental attitudes and behaviors: A U.K. case study of household waste management. Environment and Behavior, 39(4), pp. 435-473, 2007. DOI: $10.1177 / 0013916505283421$.

[21] Fornara, F., Carrus, G., Passafaro, P. \& Bonnes, M., Distinguishing the sources of normative influence on pro-environmental behaviors: The role of local norms in household waste recycling. Group Processes and Intergroup Relations, 14(5), pp. 623-635, 2011. DOI: 10.1177/1368430211408149.

[22] A-Jalil, E.E., Grant, D.B., Nicholson, J.D. \& Deutz, P., Investigating household recycling behavior through the interactions between personal and situational factors. WIT Transaction on Ecology and the Environment, vol. 180, WIT Press: Southampton and Boston, pp. 113-124, 2014.

[23] Varotto, A. \& Spagnolli, A., Psychological strategies to promote household cycling. A systematic review with meta-analysis of validated field interventions. Journal of Environmental Psychology, 51, pp. 168-188, 2017.

DOI: 10.1016/j.jenvp.2017.03.011.

[24] Han, H., Zhang, Z. \& Xia, S., The crowding-out effects of garbage fees and voluntary source separation programs on waste reduction: Evidence from China. Sustainability, 8(7), p. 678, 2016. DOI: 10.3390/su8070678. 
[25] Derksen, L. \& Gartrell, J., The social context of recycling. American Sociological Review, 58(3), pp. 434-442, 1993.

[26] Miliute-Plepiene, J., Hage, O., Plapys, A. \& Reipas, A., What motivates households recycling behavior in recycling schemes of different maturity? Lessons from Lithuania and Sweden. Resources, Conservation and Recycling, 113, pp. 40-52, 2016. DOI: 10.1016/j.resconrec.2016.05.008.

[27] Fullerton, D. \& Kinnaman, T., Household responses to pricing garbage by the bag. The American Economic Review, 86(4), pp. 971-984, 1996.

[28] Bernstad, A., la Cour Jansen, J. \& Aspegren, A., Door-stepping as a strategy for improved food waste recycling behavior - Evaluation of a full-scale experiment. Resources, Conservation and Recycling, 73, 94-103, 2013.

DOI: 10.1016/j.resconrec.2012.12.012.

[29] Kish, L., A procedure for objective respondent selection within the household. Journal of the American Statistical Association, 44(247), pp. 380-387, 1949. DOI: $10.1080 / 01621459.1949 .10483314$.

[30] Vicente, P. \& Reis, E., Factors influencing households' participation in recycling. Waste Management and Research, 26(2), pp. 140-146, 2008. DOI: $10.1177 / 0734242 \times 07077371$.

[31] Schultz, P.W. \& Zelezny, L., Reframing environmental messages to be congruent with American values. Human Ecology Review, 10(2), pp. 126-136, 2003. 